\title{
РЕГИОНОВЕДЕНИЕ
}

DOI: $10.17805 /$ ggz.2020.1.6

\section{Риски инициативы «Один пояс - один путь»}

\author{
А. А. Бучкина
}

Московский гуманитарный университет

Статья посвящена проблеме рисков для участников инициативы «Один пояс - один путь». Представленная Си Цзиньпином китайская стратегия экономического развития мало изучена, и подписавшие договоры о сотрудничестве государства должны знать о рисках, которые могут возникнуть при реализации этого проекта. В статье рассматриваются мнения экспертов из разных стран и современное состояние концепции.

Ключевые слова: инициатива «Один пояс - один путь»; риски; США; Китай; долговая ловушка; инфраструктура; инвестиции

\section{Risks of the Belt and Road Initiative \\ A. A. Buchkina \\ Moscow University for the Humanities}

The article deals with the issue of risks to the participants of the Belt and Road Initiative. The Chinese strategy for economic development proposed by Xi Jinping is insufficiently studied. The states that have ratified the cooperation agreements should know about possible risks that can appear in the realization of this project. The author examines opinions expressed by experts from different countries and current status of the conception.

Keywords: Belt and Road Initiative; risks; USA; China; debt trap; infrastructure; investments

\section{ВВЕДЕНИЕ}

Китайская инициатива «Один пояс - один путь» (кит. 一帶一路 yīdài yīlù) обычно рассматривается с точки зрения экономики (поиск экономических выгод) и политики (вероятная перемена в соотношении сил в регионе). Однако редко анализируются риски, оказывающие влияние на результаты деятельности этой инициативы в долгосрочной перспективе.

Данная статья, посвященная проблеме рисков для участников инициативы «Один пояс - один путь», написана на базе официальных источников и публикаций в российских и зарубежных СМИ и является частью исследова- 
тельского проекта «Инициатива “Один пояс - один путь”». Его актуальность обусловлена тем, что на данный момент представленная Си Цзиньпином концепция мало изучена в части рисков, которые могут возникнуть в ходе ее реализации. Основу работы составили публикации на сайте одного из ведущих мировых специализированных онлайн-изданий China-US Focus, которые представляют интерес для проводимого исследования.

При отборе материалов мы придерживались следующих принципов и критериев: 1) актуальность данных, т. е. использовались только статьи, опубликованные за последние два года; 2) наибольшее соответствие выбранной теме; 3) разносторонность мнений, так как для лучшего изучения и большего понимания сути проблемы нужно рассмотреть ее с разных сторон; 4) их авторы- представили разных стран, что необходимо для анализа политики и отношения какого-либо государства к инициативе «Один пояс - один путь».

В статье нашли отражение публикации журналистов и экспертов в сфере международных отношений, обзоры новостных событий, а также материалы саммитов, деятельность международных организаций и др.

\section{КОНЦЕПЦИЯ «ОДИН ПОЯС - ОДИН ПУТЬ»}

Инициатива «Один пояс - один путь» была выдвинута на XIX съезде Коммунистической партии Китая Си Цзиньпином. Это предложение объединенных проектов «Экономического пояса Шелкового пути» и «Морского Шелкового пути XXI века». В этом проекте планируется интегрировать экономики более 60 стран на сумму свыше $40 \%$ мирового ВВП. Инициатива направлена на создание десятков аэропортов, железных и автомобильных дорог, трубопроводов, морских портов, электростанций и другой крупной инфраструктуры на всей территории Азиатско-Тихоокеанского региона, Центральной Азии, Ближнего Востока и Африки.

США были одними из первых, кто выразил противоречивое отношение к китайскому проекту. В мае 2017 г. Дональд Трамп направил делегацию из Совета национальной безопасности на первый форум «Один пояс - один путь», тем самым показав готовность США сотрудничать в рамках данной инициативы Китая. Однако после встречи с индийскими официальными лицами в конце сентября министр обороны США Джеймс Мэттис заявил, что китайско-пакистанский экономический коридор, часть пути «Один пояс один путь», проходит через «спорную территорию», поэтому необходимо предпринять усилия для противодействия этой инициативе. 3 октября 2017 г. во время доклада в Комитете Сената США по вооруженным силам Мэттис подчеркнул, что в глобализированном мире - много поясов и много дорог, и ни одна нация не должна ставить себя в положение диктатора пути «Один 
пояс - один путь». Этот новый тон в той или иной степени был сигналом, который с тех пор разделили другие представители американской власти.

Финансовые аналитики скептически относятся к тому, что многие инфраструктурные проекты являются достойными инвестициями для Китая или стран-партнеров. Чтобы расширить сферу экономического влияния по всему миру через проект Си Цзиньпина, Китай готов на краткосрочные потери. В некоторых случаях стремящиеся участвовать в инициативе развивающиеся страны тоже готовы взять на себя часть долговых обязательств.

Например, Шри-Ланка подписала договор о передаче в аренду Китаю южного порта Хамбантота на срок 99 лет, что привело к тому, что некоторые критики провели параллели с арендой Великобританией Гонконга у Китая. Центр судоходства стоимостью 1,3 млрд долл. США открылся семь лет назад, в основном финансировался за счет китайских госкомпаний. Власти ШриЛанки так и не смогли извлечь выгоду из сделки и остались без особого выбора, кроме как предложить своим партнерам долю собственности (Bittner, 2017: Электронный ресурс).

Критики часто утверждают, что Китай использует свою инициативу «Один пояс - один путь» как форму принудительной «дипломатии долговой ловушки», чтобы установить контроль над странами, которые присоединяются к его схеме транснациональных инвестиций в инфраструктуру. Этот риск, как недавно отметила Дебора Браутигам из Университета Джона Хопкинса, часто преувеличивается СМИ (Белов, 2019: Электронный ресурс). На самом деле китайский проект «Один пояс - один путь» может содержать иной вид риска - для самого Китая (Burchill, 2019: Электронный ресурс).

На саммите в Пекине, проводившемся 25-27 апреля 2019 г., председатель КНР Си Цзиньпин признал критику «долговой ловушки». Он отметил, что «строительство высококачественной, стабильной, устойчивой к рискам инфраструктуры по умеренной цене поможет странам полностью использовать свои природные ресурсы» (“...building high-quality, sustainable, riskresistant, reasonably priced, and inclusive infrastructure will help countries to utilize fully their resource endowments"; цит. по: Huang, 2019: Электронный ресурс; пер. наш. - $A$. Б.).

Это обнадеживающий сигнал, поскольку он показывает, что Китай стал лучше понимать долговые последствия проекта. В исследовании Центра глобального развития сделан вывод, что 8 из 63 стран, участвующих в китайском проекте, находятся под угрозой «долгового бедствия» (ibid).

Китай может стать жертвой «устаревающей модели сделки», которая подразумевает, что иностранный инвестор теряет позиции на переговорах, поскольку он вкладывает в принимающую страну больше средств. Инфраструктурные проекты, подобные тем, которые осуществляются в рамках про- 
екта «Один пояс - один путь», являются классическим примером этой модели, поскольку они слишком сложные, привязаны к определенной локации и не принесут экономической пользы, если оставить их незавершенными.

В связи с этим некоторые страны-партнеры инициативы «Один пояс один путь» в настоящее время требуют пересмотра условий, как правило, уже после начала осуществления проектов. Китай, возможно, будет вынужден пойти на дополнительные уступки, чтобы сохранить проекты на прежнем уровне. Например, в середине апреля 2019 г. Малайзия объявила, что крупный железнодорожный проект, разработанный в рамках инициативы и отложенный правительством после выборов 2018 г., был возобновлен. После долгих переговоров стороны 12 апреля 2019 г. подписали новый договор, в котором цена проекта была снижена до 5 млрд долл. США, что почти в 10 раз ниже изначальной (Премьер Малайзии ..., 2019: Электронный ресурс). Другие страны проекта «Один пояс - один путь», вероятно, также попросят о списании части долгов, а расходы в конечном итоге понесут китайские инвесторы (Mengzi, Jing, 2019: Электронный ресурс).

Инициатива «Один пояс - один путь» вполне может обернуться для Китая дополнительными скрытыми затратами. Существует широко распространенное мнение, что инвестиции в инфраструктуру влияют на экономический рост, но доказательств этому немного. В 1980-е и 1990-е гг., например, Китай рос гораздо быстрее, чем Индия, несмотря на менее развитую железнодорожную сеть. По данным Всемирного банка, в 1996 г. в Китае было 56 678 км (35 218 миль) железнодорожных линий, а в Индии - 62915 км. Китайский рост был спровоцирован не инфраструктурными проектами, а реформами и инвестициями в человеческий капитал (Белов, 2019: Электронный ресурс).

Кроме того, многие страны - участники проекта «Один пояс - один путь» находятся в зоне риска, в том числе Пакистан - крупный получатель инвестиций по этой схеме. Помимо высоких политических, экономических и дефолтных рисков в стране также низки показатели образования. Согласно одному из докладов, Пакистан по уровню грамотности населения находится на 180-м месте среди 221 страны. Это создает потенциальные риски для китайских инвестиций в Пакистане, поскольку исследования говорят о том, что инвестиции в инфраструктуру способствуют росту только в странах с высоким уровнем человеческого капитала. Китай сам получает выгоду от своих инфраструктурных инвестиций, поскольку значительные средства были направлены и на развитие образования (там же).

Проект «Один пояс - один путь» не следует также сравнивать с планом Маршалла - программой США, призванной помочь восстановлению Западной Европы после Второй мировой войны, как примером того, как 
масштабные инвестиционные проекты могут стимулировать экономический рост. План Маршалла оказался столь успешен, потому что был направлен на помощь достаточно хорошо развитым странам, экономики которых столкнулись с трудностями из-за войны. Поддержка послужила толчком для развития. Некоторые страны, участвующие в китайском проекте, напротив, страдают от экономических и управленческих проблем и не имеют базовых триггеров экономического роста. Развития исключительно инфраструктуры будет недостаточно (там же).

Наконец, рассматриваемый проект еще больше может укрепить государственный сектор Китая, тем самым увеличив одну из долгосрочных угроз его экономике. Согласно исследованию Американского института предпринимательства, на долю частных фирм в первом полугодии 2018 г. пришлось лишь 28 \% инвестиций проекта Си Цзиньпина «Один пояс - один путь» (последние имеющиеся данные), что на 12 \% меньше, чем за аналогичный период 2017 г. (Huang, 2019: Электронный ресурс).

Масштаб инициативы Си Цзиньпина вкупе с низкой рентабельностью означает, что проекты по этой схеме могут нуждаться в значительной поддержке китайских банков. Проекты, осуществляемые в рамках концепции «Один пояс - один путь», затем неизбежно будут конкурировать за дополнительные средства с внутренним частным сектором Китая, который и без того сталкивается с высоким налоговым бременем и сложностями из-за торговой войны с США (Huang, 2019: Электронный ресурс; Белов, 2019: Электронный ресурс).

Кроме того, западные фирмы, важная составляющая частного сектора Китая, выводят оттуда свои производства. Такие американские компании, как Amazon, Oracle, Seagate и Uber, южнокорейские Samsung и SK Нуniх и японские Mitsubishi, Sony и Toshiba, либо сократили свое присутствие, либо решили вообще уйти. В результате прямые иностранные инвестиции США в Китай в 2017 г. составили 2,6 млрд долл. США против 5,4 млрд в 2002 г. (Хунь, 2019: Электронный ресурс).

Все это не может не вызывать опасения. Через инициативу Китай выстраивает сотрудничество с рядом наиболее авторитарных и экономически неразвитых государств мира. В то же время торговая война, все более сильный государственный сектор и протекционизм оказывают негативное влияние на отношения между Китаем и западными странами (там же).

Китай смог значительно укрепить свою экономику и развить потенциал для реализации своего проекта «Один пояс - один путь», поскольку открыл свою экономику для зарубежных компаний, используя их технологии и инновации. Однако в отличие от сотрудничества с западными партнерами «Один пояс - один путь» может нести большие риски, которые могут суще- 
ственно подорвать китайскую экономику. По мере того как экономический рост в Китае замедляется, а экспортные перспективы все больше омрачаются геополитическими проблемами, следует переосмыслить темпы и масштаб китайской инициативы (там же).

\section{ЗАКЛЮЧЕНИЕ}

Таким образом, можно сказать, что в данном проекте рискам больше всего подвержен именно его инициатор - КНР. К тому же эту концепцию поддерживают далеко не все страны, а некоторые даже открыто критикуют, например, США.

Проект Си Цзиньпина «Один пояс - один путь» обычно описывается как соглашение о сотрудничестве между государствами-единомышленниками, заинтересованными в продвижении инфраструктурных и коммуникационных проектов по всему миру. По мере расширения сферы охвата инициативы «Один пояс - один путь» с точки зрения осуществляемых проектов, задействованных участников и преследуемых целей становится очевидной необходимость более формализованной институциональной архитектуры.

\section{СПИСОК ЛИТЕРАТУРЫ}

Белов, А. (2019) Project Syndicate: Инициатива «Один пояс - один путь» несёт угрозу для КНР [Электронный ресурс] // ИА Regnum. 23 мая. URL: https://regnum.ru/news/polit/2633674.html [архивировано в WaybackMachine] (дата обращения: 22.12.2019).

Премьер Малайзии: инициатива «Один пояс - один путь» будет выгодна для всех участников (2019) [Электронный ресурс] // ТАСС. 28 апреля. URL: https://tass.ru/mezhdunarodnaya-panorama/6386430 [архивировано в WaybackMachine] (дата обращения: 22.12.2019).

Хунь, Я. (2019) Project Syndicate (США): может ли «Пояс и путь» стать ловушкой для Китая? [Электронный ресурс] // ИноСМИ. 25 мая. URL: https:// inosmi.ru/politic/20190525/245143938.html [архивировано в WaybackMachine] (дата обращения: 22.12.2019).

Bittner, P. (2017) Trump’s wavering stance on China's one belt one road [Электронный ресурс] // China-US Focus. December 21. URL: https://chinausfoc us.com/foreign-policy/trumps-wavering-stance-on-chinas-one-belt-one-road [архивировано в WaybackMachine] (дата обращения: 22.12.2019).

Burchill, R. (2019) The Belt and Road Initiative evolving into a multilateral project [Электронный ресурс] // China-US Focus. June 11. URL: https://chinaus focus.com/finance-economy/the-belt-and-road-initiative-evolving-into-a-multilater al-project [архивировано в WaybackMachine] (дата обращения: 29.12.2019). 
Huang, Y. (2019) Can the Belt and Road become a trap for China? [Электронный ресурс] // China-US Focus. May 27. URL: https://chinausfocus.com/ finance-economy/can-the-belt-and-road-become-a-trap-for-china [архивировано в WaybackMachine] (дата обращения: 12.01.2020).

Mengzi, F., Jing, Zh. (2019) New era dawns for Belt and Road [Электронный ресурc] // China-US Focus. May 14. URL: https://chinausfocus.com/financeeconomy/new-era-dawns-for-belt-and-road [архивировано в WaybackMachine] (дата обращения: 19.01.2020).

Дата поступления: 20.01.2020 г.

\section{REFERENCES}

Belov, A. (2019) Project Syndicate: Initsiativa «Odin poias — odin put'» neset ugrozu dlia KNR [Project Syndicate: The Belt and Road Initiative is jeopardizing the PRC]. IA Regnum, May 23. [online] Available at: https://regnum.ru/news/ polit/2633674.html [archived in WaybackMachine] (accessed 22.12.2019). (In Russ.).

Prem'er Malaizii: initsiativa «Odin poias — odin put'» budet vygodna dlia vsekh uchastnikov [Prime Minister of Malaysia: The Belt and Road Initiative will be profitable for all participants]. (2019) TASS, April 28. [online] Available at: https://tass.ru/mezhdunarodnaya-panorama/6386430 [archived in WaybackMachine] (accessed 22.12.2019). (In Russ.).

Huang, Y. (2019) Project Syndicate (SShA): mozhet li «Poias i put'» stat' lovushkoi dlia Kitaia? [Project Syndicate (USA): Can the Belt and Road become a trap for China?]. InoSMI, May 25. [online] Available at: https://inosmi.ru/politic/ 20190525/245143938.html [archived in WaybackMachine] (accessed 22.12.2019). (In Russ.).

Bittner, P. (2017) Trump's wavering stance on China's one belt one road. China-US Focus, December 21. [online] Available at: https://chinausfocus.com/ foreign-policy/trumps-wavering-stance-on-chinas-one-belt-one-road [archived in WaybackMachine] (accessed 22.12.2019).

Burchill, R. (2019) The Belt and Road Initiative evolving into a multilateral project. China-US Focus, June 11. [online] Available at: https://chinausfocus.com/ finance-economy/the-belt-and-road-initiative-evolving-into-a-multilateral-project [archived in WaybackMachine] (accessed 29.12.2019).

Huang, Y. (2019) Can the Belt and Road become a trap for China? ChinaUS Focus, May 27. [online] Available at: https://chinausfocus.com/finance-economy/can-the-belt-and-road-become-a-trap-for-china [archived in WaybackMachine] (accessed 12.01.2020). 
Mengzi, F. and Jing, Zh. (2019) New era dawns for Belt and Road. ChinaUS Focus, May 14. [online] Available at: https://chinausfocus.com/finance-economy/new-era-dawns-for-belt-and-road [archived in WaybackMachine] (accessed 19.01.2020).

Submission date: 20.01.2020.

Бучкина Анна Александровна - магистрант кафедры истории и регионоведения АНО ВО «Московский гуманитарный университет». Адрес: 111395, Россия, г. Москва, ул. Юности, 5. Тел.: +7 (499) 374-70-88. Эл. адрес: region@mosgu.ru

Buchkina Anna Aleksandrovna, Master's Student, Department of History and Regional Studies, Moscow University for the Humanities. Postal address: 5, Yunosti St., 111395 Moscow, Russian Federation. Tel.: +7 (499) 374-70-88. Email: region@mosgu.ru

Для цุитирования:

Бучкина А. А. Риски инициативы «Один пояс - один путь» [Электронный ресурс] // Горизонты гуманитарного знания. 2020. № 1. С. 87-94. URL: http://journals.mosgu.ru/ggz/article/view/1164 (дата обращения: дд.мм. гггг). DOI: 10.17805/ggz.2020.1.6 